\title{
Neonatal Umbilical Cord Infections: Incidence, Associated Factors and Cord Care Practices by Nursing Mothers at a Tertiary Hospital in Western Uganda
}

\author{
Munanura Turyasiima1*, Martin Nduwimana1, Silva Manuel Andres', Gloria Kiconco', \\ Walufu Ivan Egesa1, Bernis Melvis Maren¹, Robinson Ssebuufu² \\ ${ }^{1}$ Department of Paediatrics and Child Health, Faculty of Clinical Medicine and Dentistry, Kampala International University \\ Western Campus, Bushenyi, Uganda \\ ${ }^{2}$ Department of Surgery, Faculty of Clinical Medicine and Dentistry, Kampala International University Western Campus, \\ Bushenyi, Uganda \\ Email: *munanuraturyasiima@kiu.ac.ug
}

How to cite this paper: Turyasiima, M., Nduwimana, M., Andres, S.M., Kiconco, G., Egesa, W.I., Maren, B.M. and Ssebuufu, R. (2020) Neonatal Umbilical Cord Infections: Incidence, Associated Factors and Cord Care Practices by Nursing Mothers at a Tertiary Hospital in Western Uganda. Open Journal of Pediatrics, 10, 288-301. https://doi.org/10.4236/ojped.2020.102030

Received: March 8, 2020

Accepted: May 25, 2020

Published: May 28, 2020

Copyright (c) 2020 by author(s) and Scientific Research Publishing Inc. This work is licensed under the Creative Commons Attribution International License (CC BY 4.0).

http://creativecommons.org/licenses/by/4.0/ (c) (i) Open Access

\begin{abstract}
Background: Umbilical cord infections complicate to neonatal sepsis that significantly contributes to neonatal mortality worldwide. There is paucity of data on the incidence, factors associated with neonatal umbilical cord infections in western Uganda, yet nursing mothers continue to practice potentially dangerous cord care practices. We described the incidence, factors associated with umbilical cord infections and cord care practices by nursing mothers at a tertiary hospital in western Uganda. Methods: This was a hospital based cross sectional study at a tertiary hospital in western Uganda between the months of March and June 2019. Two hundred and forty (240) neonates aged between 2 to 14 days attending the neonatal unit were recruited in the study. Umbilical cord infection was assessed based on the World Health Organisation (WHO) clinical definition: finding of any of discharge, redness and swelling on the umbilical stump. Data on sociodemographic characteristics, maternal and neonatal perinatal factors and cord care practices of the nursing mothers were analysed by bivariate and multivariate logistic regression using STATA 13.0 to determine factors associated with umbilical cord infection. Results: Sixty-five, $65(27.1 \%)$ neonates had at least one sign of cord infection. Majority of the nursing mothers, $168(70 \%)$ do not use the recommended umbilical cord care practices. Among these, 73 (30.4\%) do not cleanse the cord while 95 (39.6\%) cleanse with application of a dangerous substance. Application of dangerous substance to the cord (aOR: 3.0, 95\% CI: $1.37-6.37, \mathrm{p}=0.006$ ) and maternal secondary education level $(\mathrm{aOR}=2.1, \mathrm{CI}=1.01-4.18, \mathrm{p}=0.046)$ were significantly associated with umbilical cord infection. Conclusions: The inci-
\end{abstract}


dence of neonatal umbilical cord infection is high in this setting. Application of a dangerous substance to the umbilical stump and maternal secondary education level were significantly associated with umbilical cord infection. Clinicians should routinely examine the umbilical stump of every neonate for the signs of infection and encourage mothers to avoid application of dangerous substances to the cord. Maternal education on the recommended cord care practices during antenatal and postnatal period could reduce the incidence of umbilical cord infection among neonates in low resource setting.

\section{Keywords}

Umbilical Cord Infection, Cord Care Practices, Associated Factors, Western Uganda

\section{Background}

Umbilical cord infections have for centuries caused deaths in neonates. The incidence of cord infection in neonates increased in the 1940s after the introduction of nurseries for newborns in hospitals [1]. These infections now contribute the highest risk of death due to neonatal sepsis, compared to all other causes of neonatal sepsis [2] [3] [4] [5]. Umbilical cord infection is the infection of the umbilicus and/or surrounding tissues, occurring primarily in the neonatal period. It is a true medical emergency that can rapidly progress to neonatal sepsis and death, with an estimated mortality rate between $7 \%$ and $15 \%$ [6].

According to World Health Organization (WHO), umbilical cord infection is the infection of the neonatal umbilical cord stump clinically diagnosed by the presence of any of umbilical discharge, erythema or swelling [7]. Multiple complications can occur from bacterial colonization and infection of the umbilical cord because of its direct access to the bloodstream.

Umbilical cord infection risk is $62 \%$ higher in neonates receiving topical cord applications of potentially unclean substances [4] [8]. Other common risk factors for the development of umbilical cord infection include unplanned home birth or septic delivery, low birth weight, prolonged rupture of membranes, umbilical catheterization, chorioamnionitis [9], lack of knowledge on cord care, twin's delivery [10] and prematurity [11] [12].

Chlorhexidine cord cleansing and dry cord care significantly reduces neonatal mortality related to umbilical cord infection [9] [13] [14] [15]. The incidence of umbilical cord infection reported in different communities varies greatly, depending on prenatal and perinatal practices, cultural variations in cord care, and delivery venue (home versus hospital) [9].

In developing countries, where most deliveries take place at home, some traditional practices such as applying unclean substances to the cord stump, conflict with principles of cleanliness and greatly increase the risk of cord infection and tetanus [9] [16]. These substances have included plant extracts, raisins, coins, cow dung, colostrum, and, more recently, antibiotics in the form of pow- 
ders, solutions, and/or sprays [16] [17] [18].

There is paucity of data on the incidence, factors associated with neonatal umbilical cord infections in western Uganda, yet nursing mothers continue to practice potentially dangerous cord care practices. This study described the incidence, factors associated with umbilical cord infections and cord care practices by nursing mothers at a tertiary hospital in western Uganda.

\section{Materials and Methods}

\subsection{Study Design and Setting}

This was a hospital based descriptive analytical cross-sectional study that determined the incidence, and described associated factors of umbilical cord infections and cord care practices by nursing mothers among neonates in the neonatal section of Kampala International University Teaching Hospital (KIU-TH), western Uganda.

The KIU-TH neonatal section has three divisions; the special care baby unit (SCBU) where preterm and very sick neonates are admitted, the baby nursery at maternity ward where immediate newborns are monitored for 48 - 72 hours with their mothers before discharge and the neonatal stable room where sick neonates with non life-threatening conditions are admitted for treatment. The neonatal unit provides neonatal care services including neonatal resuscitation, nasogastric feeding, intravenous fluid therapy and management of neonatal infections, prematurity, birth asphyxia and neonatal jaundice.

The section is well staffed with 3 pediatricians, 4 senior house officers (SHOs), 2 junior house officers (JHOs) and 2 general nursing officers. The doctors work on scheduled daily programs to ensure there is an attending doctor at all times. Nurses also work in shifts and are regularly trained through continuous medical education (CME) on neonatal life support and management of common newborn conditions.

The unit is equipped with ambubags, face masks, a radiant warmer, room heater, 5 incubators, 2 infusion pumps, 3 phototherapy machines, 4 oxygen concentrators and provides improvised nasal-bubble continuous positive airway pressure (CPAP)to premature neonates.

\subsection{Inclusion and Exclusion Criteria}

Two hundred and forty (240) late preterm and term neonates born between 34 and 42 weeks of gestation were consented and enrolled consecutively over a period of 4 months from March to June 2019. The study included stable neonates at the maternity nursery and those admitted at the neonatal unit and excluded early and extreme preterm neonates born below 34 weeks of gestation. This is because these neonates are under the care of the nurse who as well cares for the cord and also on the routine prophylactic antibiotics.

\subsection{Participants' Characteristics}

Socio-demographic, perinatal characteristics of the nursing mother and neonate, 
and cord care practices by the nursing mother were captured using a structured questionnaire designed by the principal investigator and pretested for reliability and validity of the data. Pre-testing of the questionnaires was done at the Neonatal Ward at Mbarara Regional Referral Hospital (MRRH) in the same geographical area, located in Mbarara Municipality, using ten (10) questionnaires. Clearance was sought from the MRRH administration before pre-testing the research questionnaires on the patients. Interviews and examination of the participants was done by the investigator(s) and this could compromise inter-rater reliability bias. However, a second opinion was always thought from the attending clinician for neonates who were found to have cord infection before being put on the treatment list for cord infection or sepsis. The questionnaires were translated into local language (Runyankole) and to ensure that the translations are correct, the questionnaires were back translated into the English and compared to assess if meanings have changed.

\subsection{Data Collection}

The study included newborns in the neonatal nursery and neonatal unit. Sick neonates first received emergency treatment as per treatment protocols. Written informed consent from the mother/father of the neonate was obtained; a study number and inpatient number was assigned to each neonate. The investigators conducted a face-to-face interview with mother/care-giver, and information regarding socio-demographic data of the neonate, perinatal factors and cord care practices documented using a structured questionnaire.

A full neonatal head to toe examination was done on every neonate with emphasis on the abdominal examination. Weight of every neonate was taken using a digital weighing scale and recorded in the respective questionnaire. Comprehensive neonatal physical examination of every neonate was done with focus on the umbilical stump for clinical signs of umbilical cord infection. Umbilical cord infection was defined as presence of any of purulent discharge, redness and/or swelling/edema around the umbilicus, according to the World Health Organization/Integrated Management of Childhood Illness (WHO/IMCI) guidelines [7].

\subsection{Statistical Analysis}

Data from completed questionnaires was arranged, summarized and entered using the statistical computer software package, Microsoft Excel 2016. The data was cleaned, checked for errors and corrected, then imported to STATA version 13.0 (Statacorp, College station, USA) for analysis.

Incidence and cord care practices by nursing mothers were analyzed and presented as frequencies and percentages. Factors associated with umbilical cord infection among neonates were analyzed using bivariate and multivariate logistic regression. Factors with p-value $\leq 0.2$ at bivariate analysis were considered for multivariate analysis. Measures of effect were reported using odds ratio for both crude and adjusted analysis, followed by corresponding $95 \% \mathrm{CI}$ and p-value. At multivariate analysis, factors with $\mathrm{p}$-value $\leq 0.05$ were considered statistically significant. 


\subsection{Study Limitations and Delimitations}

Some mothers may have hidden information related to dangerous substances applied to the cord since it is associated with social desirability bias. However, participants were encouraged and utmost confidentiality provided so that the required information was given to achieve the research objectives.

This study was hospital based and could not explore deeper into the community perspectives about cord care practices. Interviews and examination of the participants was done by the investigator(s) and this could compromise inter-rater reliability bias. However, a second opinion was always thought from the attending clinician for neonates who were found to have cord infection before being put on the treatment list for cord infection or sepsis.

\section{Results}

\subsection{Participants' Socio-Demographic and Perinatal Characteristics}

Of the 240 participants recruited, majority were young mothers aged 25 to 34 years $(45.8 \%)$, rural $(82.9 \%)$, peasants $(72.9 \%)$, and not educated beyond primary level (50.0\%) as shown in Table 1.

Table 1. Participants socio-demographic characteristics.

\begin{tabular}{|c|c|}
\hline Characteristic & Frequency, $\mathrm{n}$ [\%] \\
\hline \multicolumn{2}{|c|}{ Maternal age categories (years) } \\
\hline$<20$ & $14(5.8)$ \\
\hline $20-24$ & $93(38.8)$ \\
\hline $25-34$ & $110(45.8)$ \\
\hline$\geq 35$ & $23(9.6)$ \\
\hline \multicolumn{2}{|l|}{ Residence } \\
\hline Urban & $41(17.1)$ \\
\hline Rural & $199((82.9)$ \\
\hline \multicolumn{2}{|l|}{ Religion } \\
\hline Anglican & $128(53.3)$ \\
\hline Catholic & $73(30.4)$ \\
\hline Muslim & $14(5.8)$ \\
\hline Pentecostal & $19(7.9)$ \\
\hline Others & $6(2.5)$ \\
\hline \multicolumn{2}{|l|}{ Occupation } \\
\hline Peasant & $175(72.9)$ \\
\hline Business & $39(16.3)$ \\
\hline Formal employment & $26(10.8)$ \\
\hline \multicolumn{2}{|l|}{ Maternal education level } \\
\hline Primary or less & $120(50.0)$ \\
\hline Secondary & $81(33.7)$ \\
\hline Tertiary & $39(16.3)$ \\
\hline \multicolumn{2}{|l|}{ Maternal marital status } \\
\hline Married & $236(98.3)$ \\
\hline Single & $4(1.67)$ \\
\hline
\end{tabular}


Most of mothers were multiparous (46.2\%), had delivered by a health worker in a health facility $(98.3 \%)$ through caesarean delivery $(64.6 \%)$ and had no prolonged rupture of membranes $(88.3 \%)$. Majority of the neonates were male (51.7\%), term (90.8\%), aged below 7 days of life (95\%) with a normal average weight $(75 \%)$ and not exposed to maternal perinatal infection $(77.5 \%)$. This is shown in Table 2.

Table 2. Perinatal characteristics of mothers and neonates at Kampala International University Teaching Hospital.

\begin{tabular}{|c|c|}
\hline Characteristic & Frequency, $\mathrm{n}[\%]$ \\
\hline \multicolumn{2}{|c|}{ Maternal characteristics } \\
\hline \multicolumn{2}{|l|}{ Parity number } \\
\hline 1 & $88(36.7)$ \\
\hline $2-4$ & $111(46.2)$ \\
\hline$\geq 5$ & $41(17.1)$ \\
\hline \multicolumn{2}{|l|}{ Place of delivery } \\
\hline Home & $4(1.7)$ \\
\hline Private health facility & $216(90.0)$ \\
\hline Public health facility & $20(8.3)$ \\
\hline \multicolumn{2}{|l|}{ Mode of delivery } \\
\hline Vaginal & $85(35.4)$ \\
\hline Caesarean & $155(64.6)$ \\
\hline \multicolumn{2}{|l|}{ Gestational age (weeks of amenorrhea) } \\
\hline Term $(>37)$ & $218(90.8)$ \\
\hline Preterm $(\leq 36)$ & $22(9.2)$ \\
\hline \multicolumn{2}{|l|}{ Duration of rupture of membranes } \\
\hline Not prolonged ( $<18$ hours $)$ & $212(88.3)$ \\
\hline Prolonged ( $\geq 18$ hours) & $28(11.7)$ \\
\hline \multicolumn{2}{|l|}{ Maternal perinatal infection } \\
\hline Absent & $186(77.5)$ \\
\hline Present & $54(22.5)$ \\
\hline \multicolumn{2}{|l|}{ Education of mother on cord care } \\
\hline No & $174(72.5)$ \\
\hline Yes & $66(27.5)$ \\
\hline \multicolumn{2}{|l|}{ Cord care practice by mother } \\
\hline No cord cleansing & $73(30.4)$ \\
\hline Dry cord care and/ chlorhexidine gel & $72(30.0)$ \\
\hline Use of potentially dangerous substances & $95(39.6)$ \\
\hline \multicolumn{2}{|c|}{ Neonatal characteristics } \\
\hline \multicolumn{2}{|l|}{ Age of the neonate } \\
\hline$<7$ days & $228(95.0)$ \\
\hline $7-14$ days & $12(5.0)$ \\
\hline \multicolumn{2}{|l|}{ Neonatal birth weight (kg) } \\
\hline$<2.5$ & $180(75.0)$ \\
\hline $2.5-3.9$ & $28(11.7)$ \\
\hline$\geq 4.0$ & $32(13.3)$ \\
\hline \multicolumn{2}{|l|}{ Sex of the neonate } \\
\hline Male & $124(51.7)$ \\
\hline Female & $116(48.3)$ \\
\hline
\end{tabular}




\subsection{Umbilical Cord Care Practices by Mothers}

One hundred seventy four, 174 (72.5\%) nursing mothers had not received education by a health worker on proper cord care practices during antenatal and postnatal period, and did umbilical cord care based on advice from the attending grandmother and/or relative. Majority of the mothers 168 (70\%) do not use the recommended umbilical cord care practices. Among these, 73 (30.4\%) do not cleanse the cord while 95 (39.6\%) cleanse with application of a dangerous substance as shown in Figure 1. The commonly applied dangerous substances in cord care included: saliva, cow ghee, cow dung, herbs (ereka, mushroom, grass, kiyondo, pumpkin flower, onion leaves), ash (papyrus, matchbox), soot (saucepan, rubber), rotten yam, soil and lizard faeces in order of reducing frequency. The main reason for applying a dangerous substance was to hasten healing and cord separation.

\subsection{Incidence of Neonatal Umbilical Cord Infections}

Sixty-five $(27.1 \%)$ of the 240 neonates had at least one sign of infection on the cord. Sixty (92.3\%) of these were aged below 7 days of life and mostly male, with no statistical significance. This is shown in Table 3.

\subsection{Factors Associated with Umbilical Cord Infection}

Neonates of mothers aged 20 - 24 years $(\mathrm{uOR}=6.2 \mathrm{CI}=0.77-49.55, \mathrm{p}=0.086)$, with secondary education level $(\mathrm{uOR}=2.4, \mathrm{CI}=1.26-4.46, \mathrm{p}=0.008)$, parity one $(\mathrm{uOR}=2.1, \mathrm{CI}=0.88-5.19, \mathrm{p}=0.095)$, not received education on the recommended cord care $(\mathrm{uOR}=2.6, \mathrm{CI}=1.23-5.45, \mathrm{p}=0.012)$ and applying a dangerous substance to the cord $(\mathrm{uOR}=2.4, \mathrm{CI}=1.17-4.77, \mathrm{p}=0.017)$ were at increased odds of having umbilical cord infection at bivariate analysis. Factors significantly associated with umbilical cord infection in neonates at multivariate analysis were application of dangerous substance to the cord $(\mathrm{aOR}=3.0, \mathrm{CI}=$ 1.37 - 6.37) and secondary education level of the mother $(\mathrm{aOR}=2.1, \mathrm{CI}=1.01$ 4.18). This is shown in Table 4 and Table 5.

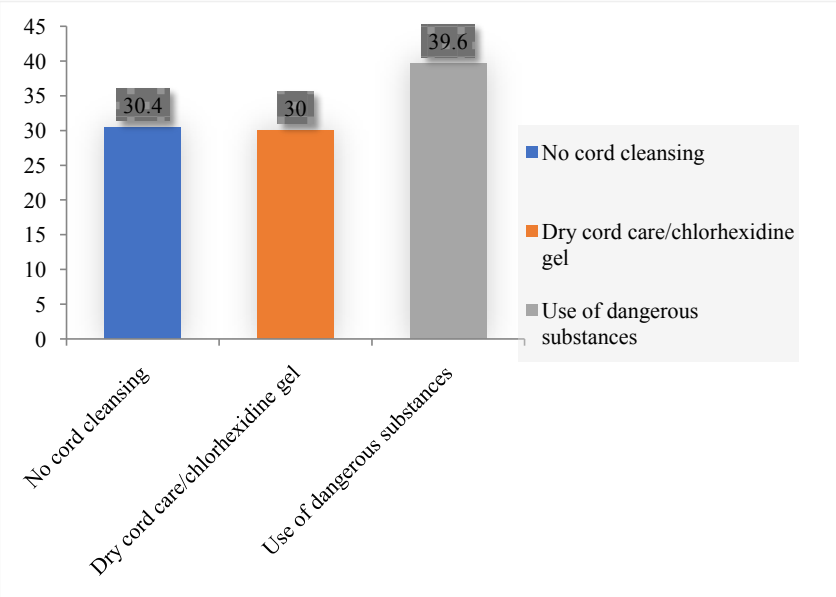

Figure 1. Umbilical cord care practices by nursing mothers. 
Table 3. Incidence of Umbilical cord infection by age and sex.

\begin{tabular}{|c|c|c|c|c|}
\hline Incidence Type & $\mathbf{N}$ & $\mathbf{n}$ & $\%$ & P-Value \\
\hline Overall & 240 & 65 & 27.1 & \\
\hline \multicolumn{5}{|l|}{ Age specific } \\
\hline$<7$ days & 228 & 60 & 26.3 & 0.243 \\
\hline 7 - 14 days & 12 & 5 & 41.7 & \\
\hline \multicolumn{5}{|l|}{ Gender specific } \\
\hline Male & 124 & 36 & 29.0 & 0.482 \\
\hline Female & 116 & 29 & 25.0 & \\
\hline
\end{tabular}

$\mathrm{N}=$ Total number, $\mathrm{n}=$ frequency.

Table 4. Results of bivariate analysis for socio-demographic, perinatal characteristics and cord care practices associated with umbilical cord infections among neonates.

\begin{tabular}{|c|c|c|c|c|}
\hline Variable & $\begin{array}{c}\text { No Cord Infection } \\
n[\%]\end{array}$ & $\begin{array}{c}\text { Cord Infection } \\
\mathrm{n}[\%]\end{array}$ & $\begin{array}{c}\text { Unadjusted OR } \\
{[95 \% \mathrm{CI}]}\end{array}$ & p-value \\
\hline \multicolumn{5}{|l|}{ Maternal age (years) } \\
\hline$<20$ & $13(92.9)$ & $1(7.1)$ & 1.0 & - \\
\hline $20-24$ & $63(67.7)$ & $30(32.3)$ & $6.2(0.77-49.55)$ & 0.086 \\
\hline $25-34$ & $79(71.8)$ & $31(28.2)$ & $5.1(0.64-40.67)$ & 0.124 \\
\hline$\geq 35$ & $20(86.9)$ & $3(13.0)$ & $2.0(0.18-20.82)$ & 0.581 \\
\hline \multicolumn{5}{|l|}{ Residence } \\
\hline Urban & $30(73.2)$ & $11(26.8)$ & 1.0 & - \\
\hline Rural & $145(72.8)$ & $54(27.1)$ & $1.0(0.48-2.17)$ & 0.968 \\
\hline \multicolumn{5}{|l|}{ Religion } \\
\hline Anglican & $91(71.1)$ & $37(28.9)$ & 1.0 & - \\
\hline Catholic & $53(72.6)$ & $20(27.4)$ & $0.9(0.49-1.76)$ & 0.819 \\
\hline Muslim & $11(78.6)$ & $3(21.4)$ & $0.7(0.17-2.54)$ & 0.557 \\
\hline Pentecostal & $17(89.5)$ & $17(10.5)$ & $0.3(0.06-1.31)$ & 0.108 \\
\hline Others & $3(50.0)$ & $3(50.0)$ & $2.5(0.28-0.60)$ & 0.284 \\
\hline \multicolumn{5}{|l|}{ Occupation } \\
\hline Peasant & $128(73.1)$ & $47(26.9)$ & 1.0 & - \\
\hline Business & $28(71.8)$ & $11(28.2)$ & $1.1(0.49-2.31)$ & 0.864 \\
\hline Formal employment & $19(73.1)$ & $7(26.9)$ & $1.0(0.40-2.54)$ & 0.994 \\
\hline \multicolumn{5}{|l|}{ Maternal education } \\
\hline Primary or none & $95(79.2)$ & $25(20.8)$ & 1.0 & - \\
\hline Secondary & $50(61.7)$ & $31(38.3)$ & $2.4(1.26-4.42)$ & 0.008 \\
\hline Tertiary & $30(76.9)$ & $9(23.1)$ & $1.1(0.17-0.41)$ & 0.767 \\
\hline \multicolumn{5}{|l|}{ Maternal marital status } \\
\hline Married & $173(73.3)$ & $63(26.7)$ & 1.0 & - \\
\hline Single & $2(50.0)$ & $2(50.0)$ & $2.7(0.38-20.0)$ & 0.318 \\
\hline \multicolumn{5}{|l|}{ Parity number } \\
\hline 1 & $58(65.9)$ & $30(34.1)$ & $2.1(0.88-5.19)$ & 0.095 \\
\hline $2-4$ & $84(75.7)$ & $27(24.3)$ & $1.3(0.55-3.22)$ & 0.533 \\
\hline$\geq 5$ & $33(80.5)$ & $8(19.5)$ & 1.0 & - \\
\hline \multicolumn{5}{|l|}{ Place of delivery } \\
\hline Home & $2(50.0)$ & $2(50.0)$ & 1.0 & - \\
\hline Private health facility & $161(74.5)$ & $55(25.5)$ & $0.3(0.47-2.48)$ & 0.289 \\
\hline Public health facility & $12(60.0)$ & $8(40.0)$ & $0.7(0.08-5.75)$ & 0.712 \\
\hline \multicolumn{5}{|l|}{ Mode of delivery } \\
\hline Vaginal & $62(72.9)$ & $23(27.1)$ & 1.0 & - \\
\hline Caesarean & $113(72.9)$ & $42(27.1)$ & $1.0(0.55-1.82)$ & 0.995 \\
\hline
\end{tabular}




\section{Continued}

\section{Gestational age \\ (weeks of amenorrhea)}

Term $(>37)$
Preterm $(\leq 36)$

Duration of rupture of membranes

Not prolonged ( $<18$ hours)

Prolonged ( $\geq 18$ hours)

Maternal perinatal infection

$$
\text { Absent }
$$

Present

Birth weight (kg)

$$
\begin{gathered}
2.5-3.9 \\
<2.5 \\
\geq 4.0
\end{gathered}
$$

\section{Sex of the neonate}

$$
\text { Male }
$$

Female

$$
\begin{gathered}
\text { Neonatal age } \\
<7 \text { days } \\
7-14 \text { days }
\end{gathered}
$$

Education of mother on cord care

$$
\begin{aligned}
& \text { No } \\
& \text { Yes }
\end{aligned}
$$

\section{Cord care practice by mother}

No cord cleansing

Dry cord care and/ or chlorhexidine gel

Use of potentially dangerous substances
$158(72.5)$

17 (77.3)

156 (73.6)

19 (67.9)

$140(75.3)$

35 (64.8)

$130(72.2)$

$23(82.1)$

22 (68.7)

88 (71.0)

$87(75.0)$

$168(73.7)$

7 (58.3)

119 (68.4)

56 (84.8)

58 (79.4)

$58(80.6)$

$59(62.1)$
60 (27.5)

5 (22.7)

56 (26.4)

9 (32.1)

46 (24.7)

$19(35.2)$

$50(27.8)$

5 (17.9)

$10(31.3)$

$36(29.0)$

$29(25.0)$

$60(26.3)$

5 (41.6)

55 (31.6)

$10(15.2)$

15 (20.6)

14 (19.4)

$36(37.9)$
1.0

$0.8(0.27-2.19)$

0.630

1.0

$1.3(0.56-3.09)$

0.522

1.0

$1.7(0.86-3.17)$

0.130

1.0

$0.6(0.20-1.57)$

$1.2(0.52-2.67)$

0.273

0.688

1.0

$0.8(0.46-1.44)$

0.483

1.0

$2.0(0.61-6.54)$

\begin{tabular}{|c|c|c|}
\hline Variable & Adjusted OR [95\% CI] & $P$-value \\
\hline \multicolumn{3}{|l|}{ Maternal age categories (years) } \\
\hline$<20$ & 1.0 & - \\
\hline $20-24$ & $6.2(0.77-49.55)$ & 0.086 \\
\hline $25-34$ & $5.1(0.64-40.67)$ & 0.124 \\
\hline $35+$ & $2.0(0.18-20.82)$ & 0.581 \\
\hline \multicolumn{3}{|l|}{ Maternal education level } \\
\hline Primary or none & 1.0 & - \\
\hline Secondary & $2.1(1.01-4.18)$ & 0.046 \\
\hline Tertiary & $0.9(0.34-2.54)$ & 0.884 \\
\hline \multicolumn{3}{|l|}{ Parity number } \\
\hline 1 & $2.1(0.59-7.16)$ & 0.255 \\
\hline $2-4$ & $1.0(0.34-2.67)$ & 0.937 \\
\hline$\geq 5$ & 1.0 & - \\
\hline \multicolumn{3}{|l|}{ Education of mother on cord care } \\
\hline No & $2.2(0.97-4.90)$ & 0.058 \\
\hline Yes & 1.0 & - \\
\hline \multicolumn{3}{|l|}{ Cord care practices by the mother } \\
\hline No cord cleansing & 1.0 & - \\
\hline Dry cord care and/chlorhexidine gel & $1.5(0.61-3.58)$ & 0.384 \\
\hline Use of dangerous substances & $3.0(1.37-6.37)$ & 0.006 \\
\hline
\end{tabular}

0.252

$2.6(1.23-5.45)$

1.0

1.0

$0.9(0.41-2.11)$

0.868

$2.4(1.17-4.77)$

0.017

Table 5. Results of multivariate analysis for factors independently associated with umbilical cord infection among neonates. 


\section{Discussion}

Umbilical cord infection is preventable and can be reduced by practicing clean delivery and clean cord care, by avoiding harmful practices, and by increasing tetanus toxoid immunization coverage [18]. In this study, the incidence of umbilical cord infection among neonates is high at $27.1 \%$. The finding is similar to other studies done in least developed countries. Studies in Uganda at China Uganda Friendship Hospital Naguru 24\% [19] and Mulago National Referral Hospital 17.2\% [20], Pumwani Maternity Hospital in Kenya 37.6\% [21], Pemba Island Tanzania 20\% [4] and Pakistan 21.7\% [22] found a high incidence of neonatal umbilical cord infection. Surprisingly, a community study in Nepal [8] found neonatal umbilical cord infection rate of 5.5\% significantly lower than the incidence from similar least developed countries, indicating that cultural practices influence the incidence compared to the economic disparities. The incidence is however several times higher compared to the few studies done in middle income and developed countries. An epidemiological study in eastern Turkey [23] put the incidence of umbilical cord infection at $11.8 \%$ while two prospective observational studies at hospitals in Oman [12] and India [5] found the incidence was even lower at $1.8 \%$ and $2.3 \%$ respectively.

The World Health Organisation [24] strongly recommends daily chlorhexidine (4\%) application to the umbilical cord stump during the first week of life for newborns who are born at home in settings with high neonatal mortality (neonatal mortality rate $>30$ per 1000 live births) and clean, dry cord care for newborns born in health facilities, and at home in low neonatal mortality settings. Use of chlorhexidine in these situations may be considered only to replace application of a harmful traditional substance such as cow dung to the cord stump [24]. This study was done on neonates born in health facilities and/or at home in low mortality setting [25].

Majority of the study participants in this study were from a rural low resource setting with less information on the recommended cord care practices compared to the participants from studies in developed settings. This has great effect on the care of the umbilical cord by mothers. About $39.6 \%$ of the mothers in this study applied a dangerous substance mostly saliva and ash to the cord of the neonate to hasten healing and/or separation; this was significantly associated with umbilical cord infection.

The odds of having umbilical cord infection were 3 times higher in neonates whose mothers applied a dangerous substance to the cord compared to neonates receiving no cord application $(\mathrm{aOR}=3, \mathrm{p}=0.006)$. Dangerous substances like saliva, ash, soil, cowdung contain pathogenic bacteria which when allowed access to the nutrient rich umbilical cord allows multiplication of the bacteria to cause umbilical cord infection.

Application of potentially dangerous substances in cord care has for long been associated with umbilical cord infection in studies done from different settings [3] [5] [8] [19]. The risk of umbilical cord infection following application of 
dangerous substance was similar to another study at China Uganda Freindship Hospital Naguru [19] which found the risk to be 3 times higher and was 20 times higher in Nepal neonates with odds risk of $62 \%$ [8] compared to neonates that receive proper cord care.

Secondary education level of the mother $(\mathrm{aOR}=2.1, \mathrm{p}=0.046)$ was another factor significantly associated with neonatal umbilical cord infection in this study. Mothers whose education level was secondary had a 2.1 times higher odd of being diagnosed with umbilical cord infection compared to those with primary level education. Lower education level has in many studies been associated with suboptimal new born care practices like application of dangerous substances to the cord [4] [5] [10] [21] [26] [27], but the finding describes how community beliefs on cord care affect umbilical cord care practices among nursing mothers irrespective of maternal level education status. The study was hospital based, so a community study would describe further on this association.

\section{Conclusions}

The incidence of neonatal umbilical cord infection is high in this setting. Application of a dangerous substance to the umbilical stump and maternal secondary education level were significantly associated with umbilical cord infection. Use of recommended cord care practices, dry cord care and/or use of chlorhexidine gel while discouraging application of dangerous substances on the cord can reduce the rate of umbilical cord infection in neonates. Education of mothers despite the level of education on proper cord care practices should be optimized by health care providers (mainly nurses and midwives) during antenatal and postnatal care package delivery. This should start with continuous medical education of midwives who deal with expectant mothers during antenatal and postnatal care.

Community sensitization by health care groups and leaders on the dangerous cultural cord care practices like the application of dangerous substances to the umbilical cord should be further promoted.

Maternal child health policy makers in least developed countries should promote application of chlorhexidine gel on the neonatal cord to replace the ues of dangerous substances. This is possible if every delivery kit supplied to the hospitals contained the chlorhexidine gel.

\section{Declarations}

Ethical approval and consent to participate: Ethical approval was sought from the research ethics committee (REC) of Kampala International University Western Campus, under reference number UG-REC-023/201901. Informed consent was sought from each mother and the purpose of the study well explained to the participants. The consent forms were in both English and local language, and the participants had the right to decline to participate or withdraw from the study at any time if they so wished. 


\section{Consent for Publication}

Not applicable.

\section{Availability of Data and Materials}

The datasets used and/or analysed during the current study are available from the corresponding author on reasonable request.

\section{Funding}

There was no special funding to this study.

\section{Authors' Contributions}

MT collected, analysed and interpreted the participants' data, also made major contributions in manuscript writng. MN, SMA, MBM, RS supervised the research and edited the manuscrpt report. GK, WIE collected participants' data and made major contributions in manuscript writng. All authors read and approved the final manuscript.

\section{Acknowledgements}

All authors appreciate the support of clinicians working in the department of paediatrics, Kampala International University Teaching Hospital for their role in patient care especially those diagnosed with umbilical cord infection during the period of study. Special thanks go to the nursing mothers of neonates who consented and participated in this study.

\section{Conflicts of Interest}

The authors declare no conflicts of interest regarding the publication of this paper.

\section{References}

[1] World Health Organisation (1998) Care of the Umbilical Cord: A Review of the Evidence. Division of Reproductive Health (Technical Support). Maternal and Newborn Health / Safe Motherhood. https://asksource.info/resources/care-umbilical-cord-a-review-evidence

[2] Grant, E., Munube, D., Lumala, P., Sentongo, S.A., Dodds, L., Bortolussi, R. and MacDonald, N.E. (2014) Neonatal Deaths and Umbilical Cord Care Practices in Luweero District, Uganda. Paediatrics \& Child Health, 19, 333. https://doi.org/10.1093/pch/19.6.333

[3] Mullany, L.C., Darmstadt, G.L., Katz, J., Khatry, S.K., Leclerq, S.C., Adhikari, R.K. and Tielsch, J.M. (2009) Risk of Mortality Subsequent to Umbilical Cord Infection among Newborns of Southern Napal. The Pediatric Infectious Disease Journal, 28, 17-20. https://doi.org/10.1097/INF.0b013e318181fb4c

[4] Mullany, L.C., Faillace, S., Tielsch, J.M., Stolzfus, R.J., Nygaard, K.E., Kavle, J.A., Farag, T.H., Haji, H.J., Khalfan, S.S., Ali, N.S., Omar, R.S. and Darmstadt, G.L. (2009) Incidence and Risk Factors for Newborn Umbilical Cord Infections on Pemba Island, Zanzibar, Tanzania. The Pediatric Infectious Disease Journal, 28 
503-509. https://doi.org/10.1097/INF.0b013e3181950910

[5] Faridi, M.M., Rattan, A. and Ahmad, S.H. (1993) Omphalitis Neonatorum. Journal of the Indian Medical Association, 91, 283-285.

[6] Painter, K. and Feldman, J. (2019) Umbilical Cord Infection. https://www.ncbi.nlm.nih.gov/books/NBK513338/

[7] World Health Organisation (2014) Integrated Management of Childhood Illness Chart Booklet. WHO Library Cataloguing-in-Publication Data.

[8] Mullany, L.C., Darmstadt, G.L., Katz, J., Khatry, S.K., LeClerq, S.C., Adhikari, R.K. and Tielsch, J.M. (2007) Risk Factors for Umbilical Cord Infection among Newborns of Southern Nepal. American Journal of Epidemiology, 165, 203-211. https://doi.org/10.1093/aje/kwj356

[9] Stewart, D., Benitz, W. and AAP Committee on Fetus and Newborn (2016) Umbilical Cord Care in the Newborn Infant. Pediatrics, 138, e20162149. https://doi.org/10.1542/peds.2016-2149

[10] Kabwijamu, L., Waiswa, P., Kawooya, V., Nalwadda, C.K., Okuga, M. and Nabiwemba, E.L. (2016) Newborn Care Practices among Adolescent Mothers in Hoima District, Western Uganda. PLoS ONE, 11, e0166405. https://doi.org/10.1371/journal.pone.0166405

[11] Evens, K., George, J., Angst, D. and Schweig, L. (2004) Does Umbilical Cord Care in Preterm Infants Influence Cord Bacterial Colonization or Detachment? Journal of Perinatology, 24, 100-104. https://doi.org/10.1038/sj.jp.7211027

[12] Sawardekar, K. (2004) Changing Spectrum of Neonatal Omphalitis. The Pediatric Infectious Disease Journal, 23, 22-26.

https://doi.org/10.1097/01.inf.0000105200.18110.1e

[13] World Health Organisation (2006) Neonatal and Perinatal Mortality: Country, Regional and Global Estimates. https://www.who.int

[14] Sinha, A., Sazawal, S., Pradhan, A., Ramji, S. and Opiyo, N. (2015) Chlorhexidine Skin or Cord Care for Prevention of Mortality and Infections in Neonates. Cochrane Database of Systematic Reviews. https://doi.org/10.1002/14651858.CD007835.pub2

[15] Karumbi, J., Mulaku, M. and Aluvaala, J. (2013) Topical Umbilical Cord Care for Prevention of Infection and Neonatal Mortality. The Pediatric Infectious Disease Journal, 32, 78. https://doi.org/10.1097/INF.0b013e3182783dc3

[16] Waiswa, P., Peterson, S., Tomson, G. and Pariyo, G.W. (2010) Poor Newborn Care Practices: A Population Based Survey in Eastern Uganda. BMC Pregnancy Childbirth, 10, 9. https://doi.org/10.1186/1471-2393-10-9

[17] Ministry of Health (2008) Situation Analysis of Newborn Health in Uganda: Current Status and Opportunities to Improve Care and Survival. Government of Uganda, Save the Children, UNICEF, WHO, Kampala.

[18] Coffey, P.S. and Brown, S.C. (2017) Umbilical Cord-Care Practices in Low- and Middle-Income Countries: A Systematic Review. BMC Pregnancy and Childbirth, 17, 68. https://doi.org/10.1186/s12884-017-1250-7

[19] Petwa, V. and Callender-Carter, S.T. (2015) Factors Influencing the Prevalence of Umbilical Cord Sepsis among Newborn Babies at the China-Uganda Friendship Hospital Naguru.

http://www.grin.com/en/ebook/307433/factors-influencing-the-prevalence-of-umbi lical-cord-sepsis-among-newborn

[20] Musoke, S.B. (2012) Umbilical Cord Sepsis among Neonates Admitted to Mulago 
Hospital: Bacterial Aetiology, Prevalence and Immediate Outcome. http://www.dspace.mak.ac.ug

[21] Joseph, L.J. (2015) Assessment of Determinants of Umbilical Cord Infection among Newborns at Pumwani Maternity Hospital. http://erepository.uonbi.ac.ke/handle/11295/94140

[22] Mir, F., Tikmani, S.S., Shakoor, S., Warraich, H.J., Sultana, S., Ali, S.A. and Zaidi, A.K. (2011) Incidence and Etiology of Omphalitis in Pakistan: A Community-Based Cohort Study. The Journal of Infection in Developing Countries, 5, 828-833. https://doi.org/10.3855/jidc.1229

[23] Güvenç, H., Güvenç, M., Yenioglu, H., Ayata, A., Kocabay, K. and Bektasl, S. (1991) Neonatal Omphalitis Is Still Common in Eastern Turkey. Scandinavian Journal of Infectious Diseases, 23, 613-616. https://doi.org/10.3109/00365549109105186

[24] World Health Organization (2017) WHO Recommendations on Newborn Health: Guidelines Approved by the WHO Guidelines Review Committee. Geneva.

[25] Uganda Bureau of Statistics (UBOS) and ICF (2018) Uganda Demographic and Health Survey 2016. UBOS and ICF, Kampala, Uganda and Rockville, MD.

[26] Lamawal, L.A., Agada, J.J., Data, A.B. and Obele, I.R. (2015) Umbilical Cord Care Practices by Traditional Birth Attendants in Yenagoa, Nigeria. IOSR Journal of Nursing and Health Science, 4, 89-96.

[27] Opara, I.P., Jaja, T., Dotimi, D.A. and Abinye, A.B. (2012) Newborn Cord Care Practices amongst Mothers in Yenagoa Local Government Area, Bayelsa State, Nigeria. International Journal of Clinical Medicine, 3, 22-27.

https://doi.org/10.4236/ijcm.2012.31004 